\title{
Design of PET Radiopharmaceuticals for Brain Imaging
}

\author{
Hsu Jyh Ping ${ }^{1,2,3}$, Chen Jenn Tzong ${ }^{1,3,4}$, Lin Jiang Jen ${ }^{1,3}$, Li Ming Hsin ${ }^{4}$, Chang Kang Wei ${ }^{4}$, Chen Dow Che ${ }^{4}$, \\ Duh Ting Shien ${ }^{4}$, Lo Pro Long ${ }^{4}$ Farn Shiou Shiow ${ }^{4}$, Luo Tsai Yueh ${ }^{4}$, Lin Wuu Jyh*5 and Shiue Chyng \\ Yann $^{6,7}$ \\ ${ }^{1}$ Department of Chemical Engineering (NTU), Taiwan \\ ${ }^{2}$ Department of Chemical Engineering (NTUST), Taiwan
}

${ }^{3}$ Institute of Polymer Science and Technology, Taiwan

${ }^{4}$ Isotope Application Department, Taiwan

${ }^{5}$ Institute of Nuclear Energy Research, Taiwan

${ }^{6}$ National Taiwan University Hospital, Taiwan

${ }^{7}$ Tri-Service General Hospital, Taiwan

*Corresponding author: Lin Wuu Jyh, Institute of Nuclear Energy Research, Taiwan

\begin{tabular}{|c|c|}
\hline ARTICLE INFO & ABSTRACT \\
\hline 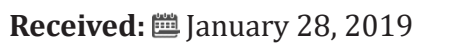 & Citation: Hsu Jyh P, Chen Jenn T, Lin Jiang J, Li Ming H, Chang Kang W, Chen Dow C, \\
\hline \multirow{2}{*}{ Published: 㓞 February 08, 2019} & Duh Ting S, Lo Pro L, Farn Shiou S, Luo Tsai Y, Lin Wuu J, Shiue Chyng Y. Design of PET \\
\hline & $\begin{array}{l}\text { Radiopharmaceuticals for Brain Imaging. Biomed J Sci \& Tech Res 14(2)-2019. BJSTR. } \\
\text { MS.ID.002527. }\end{array}$ \\
\hline
\end{tabular}

\section{Introduction}

Positron Emission Tomography (PET) is a multidisciplinary science. In contrast to CT and MRI, which are structural imaging techniques, PET is based on the characteristics of positron emitterslabeled radiopharmaceuticals and has been applied to study human pathophysiology in vivo non-invasively. In addition, PET has also been applied to monitor the efficacy of therapies, study drug pharmacokinetics (PK) and drug pharmacodynamics (PD). To design PET radiopharmaceuticals for brain neurotransmitters imaging, several factors has to be taken into consideration:

1) Binding Affinity: $0.01-1 \mathrm{nM}$;

2) Binding Selectivity and Specificity: the higher the better;

3) Lipophilicity: $\log P=1.5-4$;

4) Specific Activity: the higher the better;

5) In vivo stability;

6) Uptake kinetics; and

7) Toxicity and Radiation Dosimetry.

Alzheimer's disease (AD) is one of the most frequent causes of death and disability worldwide and has a significant clinical and socio-economic impact. Although the precise cause of $\mathrm{AD}$ remains unclear, it is most likely due to multiple etiologies such as neuronal apoptosis, inflammatory responses, and alterations in various receptors and enzymes. Thus, several PET imaging agents that target multiple mechanisms such as various receptors, enzymes and $\beta$-amyloids have been developed [1,2] for monitoring the response of $\mathrm{AD}$ drug therapy non-invasively and facilitating $\mathrm{AD}$ drugs development. $\left[{ }^{18} \mathrm{~F}\right]$ FDDNP (Figure $1 \mathrm{~b}$ ) was one of the first tau protein PET imaging radiopharmaceuticals for Alzheimer's disease and chronic traumatic encephalopathy [3]. In order to increase its lipophilicity and consequently improve its brain uptake, we have synthesized its analog $\left(\left[{ }^{18} \mathrm{~F}\right] \mathrm{FEONM}\right.$, Figure $\left.1 \mathrm{a}\right)$ and evaluated it as a potential tau protein imaging agent.

The $\left[{ }^{18} \mathrm{~F}\right]$ FEONM (Figure 2, 2) was synthesized by nucleophilic fluorination of the corresponding tosyl- precursor (Figure 2, 1) in acetonitrile with $\mathrm{K}\left[{ }^{18} \mathrm{~F}\right] / \mathrm{K}_{2.2 .2}$ at $95{ }^{\circ} \mathrm{C}$ for $15 \mathrm{~min}$ followed by purification with a semi-preparative HPLC (Fortis ${ }^{\circledR}$ Part No.

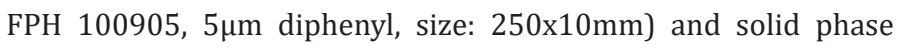
extraction gave product in $20-30 \%$ non-decay corrected yield (EOS) in a synthesis and purification time of $40 \mathrm{~min}$ from EOB. The radiochemical purity of $\left[{ }^{18} \mathrm{~F}\right] \mathrm{FEONM}$ was determined using an 
analytical HPLC (Cogent C18 100A 5 $\mu \mathrm{m}$, e Series,150mmx4.6mm, Cat.No.78018-15P). The keystep of producing F-18 labeled PET radiopharmaceuticals online is radiofluorination. One of the best reactors for radiofluorination is made of carboxy glass [4]. In carboxy glass reactor, the reaction rate of $\left[{ }^{18} \mathrm{~F}\right] \mathrm{FEONM}$ will be a first order reaction in the beginning, with $\mathrm{n}$ order reaction at time $t_{a}$ to achieve highest yield and end at time $t_{b}$, then gradually decompose with $-\mathrm{m}$ order reaction and end at time $t_{c^{*}}$. Therefore, for the function of gap area (FG) [5] curve can be approached with Gauss distribution, Gauss or Welch apodization function. Since the solution of the integration form of Gaussian apodization function is error function, cannot be found an analytical form at its minimum area by calculus. However, the length of microfluidic plug flow reactor can be designed based on Welch apodization function with an analytical form as:<smiles></smiles>

\section{a. $\left[{ }^{18} \mathrm{~F}\right] \mathrm{FEONM}$ and \\ b. $\left[{ }^{18} \mathrm{~F}\right] \mathrm{FDDNP}$}

Figure 1: Structure modification of $\left[{ }^{18} \mathrm{~F}\right] \mathrm{FDDNP}$ will increase the lipophilicity and the new structure named $\left[{ }^{18} \mathrm{~F}\right] \mathrm{FEONM}$. Therefore, the no Beta amyloid $\left[{ }^{18} \mathrm{~F}\right] \mathrm{FDDNP}$ has become an both Tau tangle and Beta amyloid uptake Alzheimer disease imaging agent $\left[{ }^{18} \mathrm{~F}\right] \mathrm{FEONM}$.<smiles></smiles>

(1)<smiles>C/C(C#N)=C(/C)c1ccc2cc(N(C)CCOCCF)ccc2c1</smiles>

(2)

\section{Precursor}

\section{2-(1-\{6-[(2-2'-p-toluenesulfonic acid -ethoxyethyl)(methyl)amino]-2- naphthyl\} ethylidene)malononitrile}

\section{[ $\left.{ }^{18} \mathrm{~F}\right]$ FEONM}

$2-(1-\{6-[(2-2)-$ $\left[{ }^{18} \mathrm{~F}\right]$ Fluoroethoxyethyl)(methyl)amino] -2-naphthyl\} ethylidene)malononitrile

Figure 2: Synthesis of $\left[{ }^{18} \mathrm{~F}\right] \mathrm{FEONM}(2)$.

$$
\mathrm{L}=\frac{t_{a} F_{A 0}}{\pi D C_{A O}\left(t_{a}-t_{b}+t_{b}{ }^{2}+t_{b}{ }^{3 / 3}-t_{c}{ }^{2}-t_{a}{ }^{3 / 3}\right)} \int_{0}^{x_{A}} \frac{1+\varepsilon_{A} x_{A}}{1-x_{A}} d x_{A}
$$

Where $\mathrm{D}$ : diameter, $\mathrm{F}_{\mathrm{A} 0}$ : feed rate, $\mathrm{C}_{\mathrm{A} 0}:\left[{ }^{18} \mathrm{~F}-\right]$ initial activity concentration, $\varepsilon_{\mathrm{A}}$ : stoichiometry, $\mathrm{x}_{\mathrm{A}}$ : conversion rate. In vitro studies showed that $\left[{ }^{18} \mathrm{~F}\right] \mathrm{FEONM}$ had higher lipophilicity than that of $\left[{ }^{18} \mathrm{~F}\right]$ FDDNP $(\log =2.20 \pm 0.17$ and $1.93 \pm 0.10$, respectively [5-7]) and the $\log \mathrm{P}$ ratio of $\left[{ }^{18} \mathrm{~F}\right] \mathrm{FEONM}$ to $\left[{ }^{18} \mathrm{~F}\right] \mathrm{FDDNP}$ is 1.14 . Thus, the lipophilicity of $\left[{ }^{18} \mathrm{~F}\right]$ FDDNP increases as expected and it gets $38 \%$ higher. This is measured with shake-flask gold standard method 
which is lower than the HPLC measuring result $[4,5]$. The measured lipophilicity difference between these two methods is about one hundred times, which is very similar to Harmine, FE@SUPPY, DASB, WAY100635 and SNAP-7941 [8] also like the trending of Harmol and FET [8].

Micro PET imaging in Streptozotocin induced Tau tangle mouse model [9] showed that the brain hippocampus uptake of $\left[{ }^{18} \mathrm{~F}\right] \mathrm{FEONM}$ in Tau tangle brain hippocampus to cerebellum $\left[{ }^{18} \mathrm{~F}\right]$ FEONM on a Tau tangle P301S/PS19 transgenic mouse model is 2.29 [5] while it is 1.78 and 1.51 in Beta amyloid Tg2576 transgenic mouse model and in a triple transgenic 3xTg mouse model which has both Tau tangle and Beta amyloid [10]. From the transgenic mouse model imaging study, we found that $\left[{ }^{18} \mathrm{~F}\right] \mathrm{FEONM}$ had uptake on both Tau tangle and Beta amyloid transgenic mouse which is different from that of $\left[{ }^{18} \mathrm{~F}\right]$ FDDNP that showed no Beta amyloid transgenic mice uptake in brain hippocampus [11].

\section{References}

1. Någren K, Halldin C, Rinne J (2010) Radiopharmaceuticals for positron emission tomography investiga tions of Alzheimer's disease. Eur J Nucl Med Mol Imaging 37(8): 1575-1593.

2. Vallabhajosula S (2011) Positron emission tomography radiopharmaceuticals for imaging brain Beta-amyloid. Semin Nucl Med 41(4): 283-299.

\section{ISSN: 2574-1241}

DOI: 10.26717.BJSTR.2019.14.002527

Lin Wuu Jyh. Biomed J Sci \& Tech Res

This work is licensed under Creative

Commons Attribution 4.0 License

Submission Link: https://biomedres.us/submit-manuscript.php
3. Barrio JR, Small GW, Wong KP, Huang SC, Liu J, et al. (2015) In vivo characterization of chronic traumatic encephalopathy using [F-18] FDDNP PET brain imaging. PNAS 112(16): E2039-E2047.

4. Hamaker K, Blessing G, Nebeling B (1990) Computer aided synthesis (CAS) of no-carrier-added $2-\left[{ }^{18} \mathrm{~F}\right]$ fluoro-2-deoxy-D-glucose: an efficient automated system for the aminopolyether-supported nucleophilic fluorination. Appl Radiat Isot 41(1): 49-55.

5. Hsu JP, Chen JT, Lin SH, Chu KY, Tu YH, et al. (2016) Radiofluorination process development and tau protein imaging studies of [F-18] FEONM. J Taiwan Inst Chem Eng 68: 119-129.

6. Luurtsema G, Schuit RC, Takkenkamp K, Lubberink M, Hendrikse NH, et al. (2008) Peripheral metabolism of $\left[{ }^{18} \mathrm{~F}\right]$ FDDNP and cerebral uptake of its labelled metabolites. Nucl Med Bio 35(8): 869-874.

7. Chang KW, Chen CC, Lee SY, Wang HE (2009) Acute toxicity of two Alzheimer's disease radiopharmaceuticals: FDDNP and IMPY. Drug and Chemical Toxicology 32(4): 429-437.

8. Vraka C, Nics L, Wagner KH, Hacker M, Wadsak W, et al. (2017) LogP, a yesterday's value? Nucl Med Bio 50: 1-10.

9. Pradip KK (2015) Streptozotocin induced Alzheimer's disease like changes and the underlying neural degeneration and regeneration mechanism. Neural Regen Res 10(7): 1050-1052.

10. Kane AE, Shin S, Wong AA, Fertan E, Faustova NS, et al. (2018) Sex differences in healthspan predict lifespan in the $3 \times \mathrm{Tg}-\mathrm{AD}$ mouse model of alzheimer's disease. Front Aging Neurosci 10:172.

11. Kuntner C, Kesner AL, Bauer M, Kremslehner R, Wanek T, et al. (2009) Limitations of small animal PET imaging with $\left[{ }^{18} \mathrm{~F}\right]$ FDDNP and FDG for quantitative studies in a transgenic mouse model of Alzheimer's disease. Mol Imaging Biol 11(4): 236-240.

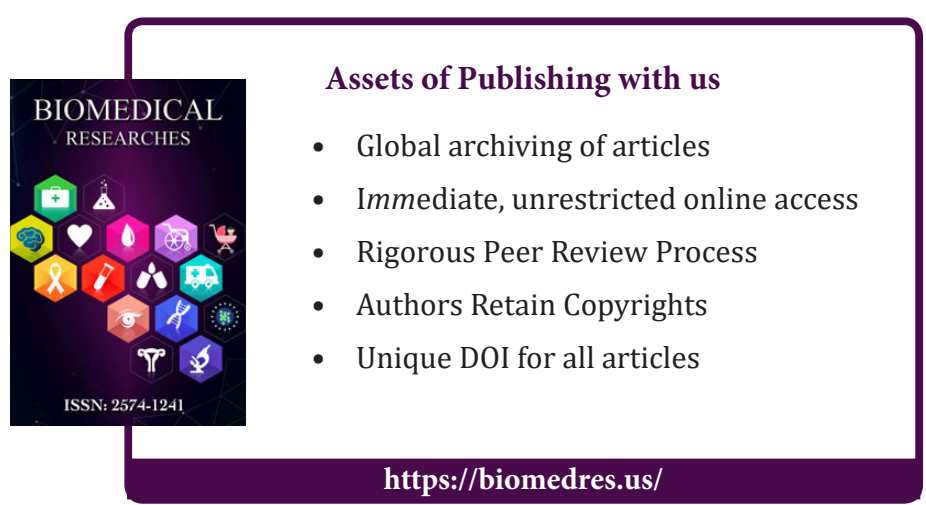

